\title{
Our Choice Improves Use of Safer Conception Methods Among HIV Serodiscordant Couples in Uganda: A Cluster Randomized Controlled Trial Evaluating Two Implementation Approaches
}

\author{
Glenn Wagner ( $\sim$ gwagner@rand.org ) \\ RAND Corp \\ Rhoda Wanyenze \\ Makerere University, School of Public Health \\ Jolly Beyeza-Kashesya \\ Makerere University \\ Violet Gwokyalya \\ Makerere University \\ Emily Hurley \\ Children's Mercy Research Institute \\ Deborah Mindry \\ UCLA: University of California Los Angeles \\ Sarah Finocchario-Kessler \\ University of Kansas Medical Center \\ Mastula Nanfuka \\ TASO: AIDS Support Organisation \\ Mahlet Tebeka \\ Pardee RAND Graduate School \\ Uzaib Saya \\ Pardee RAND Graduate School \\ Marika Booth \\ RAND Corp \\ Bonnie Ghosh-Dastidar \\ RAND Corp \\ Sebastian Linnemayr \\ RAND Corp \\ Vincent Staggs \\ Children's Mercy Research Institute \\ Kathy Goggin \\ Children's Mercy Research Institute
}

\section{Research}

Keywords: HIV, safer conception counseling, contraception, family planning, Uganda, serodiscordant couples, safer conception methods, timed condomless intercourse, manual self-insemination

Posted Date: January 13th, 2021

DOI: https://doi.org/10.21203/rs.3.rs-143444/v1

License: (c) (i) This work is licensed under a Creative Commons Attribution 4.0 International License. Read Full License 
Version of Record: A version of this preprint was published at Implementation Science on April 15th, 2021. See the published version at https://doi.org/10.1186/s13012-021-01109-z. 


\section{Abstract}

Background: Safer conception counseling (SCC) to promote safer conception methods (SCM) is not yet part of routine family planning or HIV care, and to date there are no published controlled evaluations of SCC.

Methods: In a hybrid, cluster randomized controlled trial, six HIV clinics were randomly assigned to implement the SCC intervention Our Choice using either a high (SCC1) or low intensity (SCC2) approach, or existing family planning services (usual care). 389 HIV clients considering childbearing with an HIV-negative partner enrolled. The primary outcome was self-reported use of appropriate reproductive method (SCM if trying to conceive; modern contraceptives if not) over 12 months or until pregnancy.

Results: The combined intervention groups used appropriate reproductive methods more than usual care [20.8\% vs. $6.9 \%$; adjusted OR $(95 \% \mathrm{Cl})=10.63(2.79,40.49)]$, and SCC1 reported a higher rate than SCC2 [27.1\% vs. $14.6 \%$; OR $(95 \% \mathrm{Cl})=4.50(1.44,14.01)]$. Among those trying to conceive, the intervention arms reported greater accurate use of SCM compared to usual care [24.1\% vs. $0 \%$; OR $(95 \% \mathrm{Cl})=91.84(4.94,1709.0)]$, and SCC1 performed better than SCC2 [34.6\% vs. $11.5 \%$; OR $(95 \% \mathrm{Cl})=6.43(1.90,21.73)]$; the arms did not vary on modern contraception use among those not trying to conceive. A cost of $\$ 631$ per person was estimated to obtain accurate use of SCM in SCC1, compared to \$1014 in SCC2.

Conclusions: More intensive training and supervision leads to greater adoption of complex SCM behaviors and is more costeffective than the standard implementation approach.

Trial registration: Clinicaltrials.gov, NCT03167879; date registered May 23, 2017; https://clinicaltrials.gov/ct2/show/NCT03167879.

\section{Contributions To The Literature}

- This hybrid cluster randomized controlled trial is the first to examine two approaches of implementing a safer conception counseling intervention for HIV serodiscordant couples.

- The study finding that the implementation approach with enhanced provider training and supervision was superior to the standard implementation approach in terms of cost-effectiveness and increasing use of safer conception methods, provides further evidence of the importance of these two key components of rolling out new health services.

- This finding that adequate training and ongoing supervision are essential in promoting adoption of complex health behaviors, is applicable to the management of many chronic illnesses.

\section{Background}

Approximately $40 \%$ of HIV-infected women in Uganda become pregnant after HIV diagnosis [1, 2], and roughly half of these pregnancies are planned [2]. With $60 \%$ of HIV-affected couples in Uganda being serodiscordant [3], comprehensive family planning (FP) services are needed to help persons living with HIV (PLHIV) and their partners make informed childbearing decisions, and use effective methods for either safely conceiving or preventing unplanned pregnancies.

Despite FP services being integrated into HIV care, providers rarely discuss childbearing with clients prior to pregnancy [4]. HIV risk for serodiscordant couples is nearly eliminated by effective use of antiretroviral therapy (ART) [5], and while most are on ART [6], over a third of those on ART have unsuppressed viral load [6], and few seronegative partners in sub-Saharan Africa have access to pre-exposure prophylaxis (PrEP) [7, 8]. Safer conception methods (SCM) complement ART in promotion of safer conception, but knowledge of SCM is poor [9], and our prior study of 400 PLHIV trying to conceive found just 35\% used SCM [10].

Providers could facilitate an informed childbearing decision-making process with periodic childbearing discussions. Clients could then be offered contraception to prevent pregnancy, or safer conception counseling (SCC) for effective SCM use if trying to conceive. SCC guidelines for PLHIV exist [11], but have not resulted in SCC being integrated into FP or HIV care. No randomized controlled trials of SCC were identified in a 2018 systematic review [12]; however, a prospective observational cohort study of 334 couples offered SCC found that many were able to use SCM to successfully conceive without any seroconversions [13]. 
We conducted a cluster randomized controlled trial that compared usual care to two modes of implementing a SCC intervention named Our Choice. The study had two main objectives: (1) to determine the efficacy of Our Choice versus usual care on the primary outcome of accurate use of SCM or modern contraceptives consistent with client's reproductive goal, and (2) to evaluate high versus low intensity approaches to implementing Our Choice in terms of effects on the primary outcome and cost-

effectiveness. We hypothesized that Our Choice would result in greater use of the appropriate reproductive method than usual care, and the more intensive implementation approach would lead to better uptake than the less intensive implementation approach, and be more cost-effective.

\section{Methods}

\section{Study design}

The study design was a three-arm cluster-randomized controlled trial conducted at six HIV clinics operated by The AIDS Support Organization (TASO). A cluster design was used to limit risks of contamination biases across treatment conditions. Randomization and masking. Using a blind manual drawing, clinics were randomly assigned to one of three conditions by the project director: one of two implementation approaches for integrating SCC into FP services (more intensive=SCC1, less intensive=SCC2) or usual care (existing FP services). Allocation was not concealed to providers, nor individual participants (although clients did not know if their clinic was SCC1 or SCC2). The assigned condition was applied clinic-wide for all clients.

Participants completed assessments at baseline, month 6 and month 12. If the client experienced a pregnancy by month 12 , the final study assessment was conducted approximately one month after pregnancy completion. Participants were followed as long as they were still in a relationship with the partner they enrolled with at baseline; if they separated from this partner mid-study, the next assessment would be their final, unless they had an ongoing pregnancy which would lead to an assessment at the completion of that pregnancy. The protocol was approved by Institutional Review Boards at TASO and RAND, and described in a prior publication [14]. The research conformed to the principles embodied in the Declaration of Helsinki. The trial was registered with the $\mathrm{NIH}$ clinical trial registry (clinicaltrials.gov) and assigned the number NCT03167879.

Patient and Public Involvement. HIV clients provided input into the intervention development and outcome measures through participation in prior research that involved piloting the intervention and formative research including focus groups and in-depth interviews. Furthermore, HIV clients who volunteer as "expert clients" at the clinic sites were involved in aspects of implementing the intervention including community outreach and childbearing screening. These same clients will also be involved in dissemination of the study findings.

\section{Study setting and participants}

TASO is the oldest indigenous non-governmental organization in Uganda providing comprehensive HIV care. Each site provides care to 6,000-8,000 clients and has a staff of 15-20 medical providers. Clients were eligible if they met the following criteria: 1) in a serodiscordant relationship (partner's HIV-negative status confirmed by rapid HIV test prior to enrollment), 2) of reproductive age (men age 15-60 years; women age 15-45), 3) considering childbearing with their partner (determined via triage screening item), 4) not currently pregnant (determined by a pregnancy test prior to enrollment), and 5) reports having disclosed HIV status to partner. Recruitment was stratified by sex to ensure a 50/50 balance and took place between July 2017 and January 2019. Clients who were potentially eligible were informed of the study by clinic staff and referred to the study coordinator for consent procedures. All enrolled participants provided written informed consent.

\section{Intervention conditions}

Our Choice. Informed by our earlier research $[10,15]$ and guided by an ecological adaptation of the Information, Motivation and Behavioral skills (elMB) model of behavior change [16], we developed a multi-component, structured intervention that engages HIV clients and their partners with fertility desires in SCC. The goal of the Our Choice intervention is for providers to facilitate an informed childbearing decision making process and support each couple's decision with training on the use of contraception or SCM in accordance with their reproductive goal. The intervention components are: 1) Client outreach to increase awareness and uptake of services, 2) Routine screening of childbearing desires at triage, and 3) Provision of SCC, starting with an initial consult 
conducted by an HIV counselor to facilitate an informed decision from the couple to pursue or delay pregnancy, followed by subsequent referral to FP nurses for either provision of contraception or monthly SCC sessions (see Supplement Figure 1). The client's partner was encouraged to attend sessions, if possible. SCC was implemented by trained FP nurses, using a structured protocol and manual, the content of which is summarized in Supplement Table 1.

Low vs. high intensity approaches to implementation. Our Choice was implemented using two approaches, SCC1 and SCC2; both used the same content, manual and tools, but differed on the method, duration and frequency of training and supervision of FP nurses and HIV counselors (see Supplement Table 2). SCC1 was the more intensive approach, with the study team providing initial training of providers over two days and supervision starting twice-a-month before transitioning to monthly contact at month 6 . SCC2 was less intensive and followed the standard model used by the Uganda Ministry of Health (MoH) to integrate new services: initial one day training and quarterly supervision sessions (although in reality supervision occurred every 6-9 months) provided by $\mathrm{MoH}$ supervisors who had been trained by the study team.

Usual care control. Control sites received no training and provided FP services as usual, with no use of routine screening of childbearing desires or SCC.

\section{Measures}

Assessments included measures of the primary outcome (see below), secondary outcomes (any use of SCM/contraception, pregnancy, partner seroconversion), and sociodemographic, HIV disease, and relationship/partner characteristics, as well as reproductive history and behaviors (see Table 1). Self-report measures underwent a translation, back-translation and group consensus review process in Luganda and Runyakitara (local languages used in the study settings) [17], and were intervieweradministered using computer-assisted software. All measures were assessed at each assessment time point.

\section{Primary Outcome}

The primary outcome was the accurate use of SCM [timed condomless intercourse (TCl), manual self-insemination (MSI), sperm washing] or modern contraception consistent with the client's reproductive goal. This goal was determined at follow-up assessments by asking whether they had tried to conceive a child with their partner at any time in the past 6 months. Clients with missing responses were classified as trying to conceive if they endorsed "currently trying to conceive" at their most recent prior assessment. To assess accurate use of SCM, clients were asked in an open-ended format to describe exactly how they implemented their chosen SCM. Interviewers listened, probed for specific criterion not spontaneously mentioned, and rated the presence or absence of pre-defined criterion for each SCM (see Supplement Table 3). All criteria needed to be present for clients to be classified as accurately using the method. Accurate use of contraception was defined as using modern contraception as defined by FP practice in Uganda [18]. Clients were asked if they or their partner were currently using modern contraception methods (i.e., birth control pills, medroxyprogesterone acetate injection, intrauterine device, implant, tubal ligation/vasectomy and condoms), condoms or abstinence. Male participants were asked to consent to the interviewer calling their partner during the interview to assess use of contraception (calls were made in private and responses were not shared with the male partner). We also assessed an alternative outcome that combined use of modern contraception, consistent condom use or abstinence to allow for comparison to other studies.

\section{Data Analysis}

With a planned sample size of 400, enrolled evenly across 6 sites, and using an intra-class correlation (ICC) of 0.01 and assumed attrition of $10 \%$ attrition at month 12 , our power analysis determined we would have $>80 \%$ power (2-tailed test) to detect a 4.5 percentage point difference (small effect size) for our comparison of the usual care arm to the combined SCC1 \& SCC2 arms on the primary outcome, and a 7-8 percentage point difference between the SCC1 and SCC2 intervention arms.

We conducted initial bivariate analyses to compare the study arms on baseline measures of sociodemographic characteristics, HIV disease characteristics, partner/relationship characteristics, and reproductive health history/behavior for participants. We assessed differences using chi-square or Fisher's exact test (FET) for categorical variables, and two-tailed independent t-tests for continuous variables. We repeated this analysis to compare those who completed the study with those who dropped out. 
The primary analyses followed an intent-to-treat (ITT) approach (i.e., outcomes with missing data are designated as not engaging in the desired behavior or achieving the desired pregnancy status) and had two main objectives. First, to examine efficacy of Our Choice, we examined whether the primary outcome was more prevalent in the intervention group (SCC1 and SCC2 combined) compared to the usual care group. Second, we examined the relative efficacy of the two implementation approaches to administering Our Choice by comparing the effects of the higher intensity SCC1 versus the lower intensity SCC2. In both analyses, we first conducted bivariate chi-square or Fisher's exact tests to assess associations between the outcome and treatment condition. We further tested for a significant association using covariate-adjusted Firth logistic regressions [19, 20]. Each logistic regression was adjusted for these covariates: age, sex, any secondary education, time since HIV diagnosis, marital status, length of relationship with partner, and whether the participant had a child with their partner. The model included fixed effects for site to account for clustering and allow for time-invariant differences across sites. (A mixed model approach was not possible for outcomes with quasi-separation or all zero values as was observed in the usual care arm). We relied on the effect sizes (estimated by the differences across study arms) as demonstration of practically significant results. Effect sizes were estimated using Cohen's $d$. This same approach was used to examine effects on the secondary outcomes. We replicated all analyses with study completers only. The results of this analysis (not presented) were very similar to that of the ITT analysis.

Cost-effectiveness Analysis. We conducted a cost-effectiveness analysis based on program costs for personnel, supervision, training, and materials across both active study arms. Personnel costs included those for counselors, nurses and expert clients, who over the course of the study were asked to recall how much time they spent weekly delivering intervention activities.

Supervision costs were estimated by multiplying the duration of supervision sessions by the respective supervisor's hourly salary and number of supervisory sessions conducted and including any transportation costs. Training costs included those for the initial trainings for providers (including transport and per diem), as well as any refresher trainings conducted, and costs incurred for training supervisors. Material costs included those for brochures, videos, phone top-ups for nurses, and transport for participants.

To examine the cost-effectiveness of the two different implementation approaches used in SCC1 and SCC2, we compared total intervention costs across the two active study arms for the primary outcome. Because this is one of the first analysis of SCC in this setting, we also assessed the costs for accurate use of SCM on its own among those trying to conceive. The cost-effectiveness of contraception provision in Uganda has already been established [21]. Because supervisors in SCC1 were research staff with significantly higher salaries than the $\mathrm{MoH}$ supervisors in SCC2, we conducted an additional more realistic "scale-up scenario" showing the costs of SCC1 if its supervisors' salaries were the same as the MoH supervisors' salaries. The cost-effectiveness ratio was calculated as the cost per participant divided by the relative effect size in that group compared to the usual care control. Costs in local currency were converted at 3600 Ugandan Shillings=US \$1 and reported in 2020 prices adjusted for inflation.

\section{Results}

\section{Sample Characteristics}

In each of the three study arms, 130 clients consented and enrolled; the partner of one client in the SCC1 arm tested seropositive during screening, so this client was administratively removed. Therefore, a total of 389 clients comprise the study sample (129 in SCC1 and 130 in each of SCC2 and usual care arms). Figure 1 depicts the flow of participants through the assessment protocol. Sixteen participants (4.1\%) were lost to follow-up either before the month $6(n=6)$ or month $12(n=10)$ assessments. Those lost to follow-up were similar to study completers with respect to baseline characteristics, except participants in SCC1 were more likely to be female compared to the usual care group (see Table 2). No harms or unintended negative events attributed to the intervention were reported, although 16 participants reported separating from their partner.

Fidelity to Our Choice intervention. Compared to SCC2, more participants in SCC1 received the initial safer conception consult [127 $(98.4 \%)$ vs. $115(88.5 \%) ;$ FET $=.002$ ] and follow-on SCC or FP services consistent with their reproductive goals [116 (89.9\%) vs. 94 (72.3\%); $\mathrm{p}=.001$ ). Among those who decided to pursue childbearing after the initial consult ( $\mathrm{n}=105$ in SCC1 and 87 in SCC2), $85.7 \%$ $(n=90)$ of those in SCC1 received additional SCC sessions [mean (SD) of 3.4 (2.2) added sessions; median = 3; range: 1-9], compared to $64.4 \%(n=56 ; p=.001)$ of those in SCC2 [mean (SD) of 3.0 (1.5) added sessions; median=3; range 1-7]. In SCC1, 91.3\% $(116 / 127)$ of the partners attended the initial safer conception consult, and 70.0\% (63/90) attended at least one of the successive SCC sessions, while in SCC2, $60.9 \%$ (70/115) of partners attended the initial consult and $58.6 \%(51 / 87)$ attended at least one SCC 
session. Of those in SCC1 who received SCC sessions to promote childbearing, 18.8\% (15 of the 80 who provided such data) never established a stable menstrual pattern to allow for the use of SCM, and another $30.0 \%(24 / 80)$ were only able to establish two stable menstrual cycles which allowed for only one SCM attempt. Comparable data were not consistently recorded in SCC2.

\section{Intervention Effects on Primary and Secondary Outcomes}

Table 3 lists the group comparisons on all primary and secondary outcomes, with and without covariate adjustment, and using an ITT analysis ( $p$ values listed in the text are from the adjusted models).

Intervention effect on use of appropriate reproductive method. The combined intervention group (SCC1/SCC2) reported a higher rate of accurate SCM use (TCl or MSl; sperm washing was not reported by anyone) or modern contraception consistent with their reproductive goal, compared to the usual care group (20.8\% vs. $6.9 \% ; p=.001$; Cohen's $d=.38)$. A similar result was found when using the alternative definition of appropriate contraception (i.e., use of modern contraception, consistent condom use or sexual abstinence; see Table 3).

Intervention effects on SCM use among those trying to conceive. Among the subgroup of 276 participants who reported trying to conceive throughout the study ( $n=212)$ or during one 6-month period $(n=64)$, the combined intervention group reported higher accurate SCM use (24.1\%) compared to the usual care group which had no accurate use of SCM ( $\mathrm{p}=.002$; Cohen's $d=.67)$. The combined intervention group also reported higher SCM use in general (regardless of accuracy), as well as higher TCl use, accurate TCl use, and MSI use (see Table 3). PrEP, which became available at three of the six sites midway through the final year of intervention implementation, was used by just 13 participants.

Among those in the intervention groups who reported using $\mathrm{TCl}$ or $\mathrm{MSI}$, all received calls from the nurse counselor to inform them when the woman's most fertile 3-day period was beginning; therefore, the high levels of inaccuracy for TCl were related to not knowing that the most fertile period was 3 days (30-43\% across both follow-up assessments), not having condomless sex during the most fertile period (66-76\%), and not always using condoms outside the most fertile period (67-74\%). The inaccuracy of MSI use was mostly due to not knowing that the most fertile period was 3 days (38\%), not injected semen into woman's vagina during her most fertile period (69\%), the woman not remaining in proper position for at least 30 minutes after the injection of semen (54\%), and not always using condoms during sex (46\%).

Intervention effects on modern contraception use among those trying to avoid pregnancy. In the subgroup of 177 participants who reported trying to avoid pregnancy throughout the study $(n=113)$ or during one 6-month period $(n=64)$, the combined intervention group (17.4\%) demonstrated similar level of use of modern contraceptives as the usual care group (17.6\%; $p=.832)$. There were also no noteworthy differences when using the alternative definition of modern contraception, consistent condom use or abstinence (see Table 3).

Intervention effects on pregnancy and partner seroconversion. Among the subgroup of 276 participants who tried to conceive, the pregnancy rate did not differ between those in the combined intervention group (31.9\%) compared to the usual care group (31.8\%; $\mathrm{p}=.902$ ). We examined bivariate correlates of pregnancy during the study among the 265 study completers who reported trying to conceive at either of the follow-up assessments (see Supplement Table 4). Younger woman's age was positively associated with having a pregnancy, while either partner having ever been tested for infertility or being told by a healthcare provider that they may have infertility problems was associated with not having a pregnancy. Among those who tried to avoid pregnancy, the proportion who did not get pregnant did not differ between the combined intervention group (89.9\%) and usual care group (89.7\%; $p=.289)$.

Only one partner (in SCC2) tested HIV-positive at study endpoint; he and his partner did not use SCM during the study.

\section{Effects of High (SCC1) Versus Low (SCC2) Intensity Intervention on Primary and Secondary Outcomes}

As shown in Table 3, SCC1 reported a higher rate of accurate SCM or modern contraceptive use (27.1\%) consistent with their reproductive goal, compared to SCC2 (14.6\%; $=.010$; Cohen's $d=.31)$. Among those trying to conceive during the study, SCC1 had a higher rate of accurate SCM use (34.6\% vs. $11.5 \%$; $=.003$; Cohen's $d=.56)$, as well as higher SCM use in general, accurate TCl use and TCl use, compared to SCC2; SCC1 had a similar pregnancy rate as that of SCC2 in this subgroup (30.8\% vs. 33.3\%; p=.760). SCC1 and SCC2 did not differ on contraception use or pregnancy rate, among those trying to avoid pregnancy. 


\section{Cost-effectiveness of SCC1 vs. SCC2}

The cost per client for use of appropriate reproductive methods (SCM or modern contraception, depending on reproductive goal) ranged from \$105-176 across the "scale-up" and "actual" scenarios in SCC1, and was \$78 in SCC2. The cost per client for accurate SCM use ranged from \$130-218 across these scenarios in SCC1 and was \$117 in SCC2. The cost-effectiveness ratio (or the cost per additional person treated to achieve the outcome) for use of appropriate reproductive method was \$520-871 in SCC1 for the "scale-up" and "actual" costs scenarios, and \$1014 in SCC2. For the accurate SCM outcome alone, it was \$377-631 in SCC1 and $\$ 1014$ in SCC2. Therefore, even under the more costly research implementation scenario ("actual"), SCC1 is more cost effective, and becomes the dominant strategy by a factor of 2 to 3 under the "scale-up" calculation that uses more realistic supervisor salaries, alleviating potential concerns that cost uncertainties or biases underlie our result.

\section{Discussion}

In what may be the first randomized controlled trial of a SCC intervention for PLHIV, Our Choice was superior to usual care in helping clients use recommended methods for achieving their self-proclaimed reproductive goal, namely accurate use of SCM or modern contraceptives. Compared to usual care, Our Choice was most successful in enabling more clients to accurately use SCM when trying to conceive, and produced similar rates of modern contraception use among those trying to prevent pregnancy. Furthermore, the approach to implementing Our Choice that included more intensive training and supervision was more successful in increasing accurate SCM use than the standard implementation approach.

One of the main study objectives was to determine whether Our Choice was more efficacious than usual care in helping clients and their partners to accurately use SCM if they were trying to have a child. For such clients, the intervention's magnitude of effect was large. Almost no participants in the usual care control group reported using SCM, which is not surprising given that SCC has not been integrated into standard FP practices, and thus awareness is poor [10,15]. Nearly two-thirds of intervention participants reported using SCM, with most couples using TCI. Some also used MSI, which is noteworthy given that our qualitative research found that couples often resisted this method and were skeptical of its "unnatural" method of conception [10]. Just over one-third of those using SCM used the methods accurately, but more than half of these participants (or their partners) who used SCM exhibited irregular menstrual cycles that precluded attempting these methods (and likely indicates infertility). Future studies that include women with regular menstrual cycles are needed to establish better estimates of the true impact of SCC on accurate SCM use. Additionally, studies that examine the rate and any mutable causes of infertility would help to clarify the clinical value of widespread dissemination of SCC.

The other main objective of the study was to determine if the more intensive approach was needed to achieve better results. Our data clearly show that the high intensity approach (SCC1) resulted in greater use of SCM (TCl in particular). One third of SCC1 participants trying to conceive used accurate SCM, compared to just one tenth of those in SCC2. These findings may be attributed to the more extensive training (two versus one day, and inclusion of motivational interviewing techniques) and once- or twicemonthly supervision in SCC1 compared to every 6-9 months in SCC2. Our process data also revealed the greater likelihood of SCC1 participants receiving the initial safer conception consult and follow-on SCC/FP services, as well as greater partner attendance in sessions, all of which may be attributable to the enhanced training and supervision. These findings contribute to evidence from implementation science that suggests the importance of adequate training and ongoing supervision to successfully integrate new services into routine care [22], as well as the body of literature suggesting that multi-level, properly implemented interventions are required to produce change in complex behaviors [23-25].

While the low intensity implementation approach has lower up front cost and may therefore appear more sustainable, our findings indicate that the resources needed to implement the more intensive approach were in fact more cost-effective by a factor of two to three. This further supports the merits of implementation approaches that ensure adequate training and ongoing support for new services that promote complex health behaviors. Policy evaluations for whether to integrate SCC into FP services for PLHIV will likely hinge on the important factors of ART use, viral suppression, and access to fertility testing. Unlike our study sample, scenarios where ART is not being used or HIV virus is not fully suppressed, and both partners are fertile, could greatly increase the value of implementing SCC to promote prevention of horizontal transmission and safe conception. 
Limitations to this study include the absence of survey data from the partner of the index participant, except for female partners of male participants who were briefly interviewed on contraception use. Other limitations include the reliance on self-report data, including use of SCM and contraceptives, and the sample being comprised solely of PLHIV receiving HIV care. Our findings may not reflect PLHIV who are not in HIV care and perhaps less likely to be familiar with safer conception and contraception methods and how to use them. Furthermore, evaluating the intervention in serodiscordant couples not using ART, with no infertility issues, could reveal dramatically increased benefits of SCM use for prevention of horizontal transmission and successful safe conception.

\section{Conclusions}

The results of this novel study provide evidence of the beneficial effects of the Our Choice intervention on uptake of SCM among HIV serodiscordant couples. The efficacy and cost-effectiveness of the high intensity implementation approach highlight the critical need for adequate training and ongoing supervision to successfully implement SCC and promote accurate use of complex health behaviors. The implication of these implementation approach findings may be significant for other chronic diseases where adoption of complex behavioral skills are critical for clients' health. The intervention did not affect contraception use among those trying to avoid pregnancy, suggesting the need for supplementary efforts to impact this target behavior. A minority of couples trying to conceive were successful, including those accurately using SCM, highlighting the potential role of infertility in this population and the need for further research in this area.

\section{Abbreviations}

ART Antiretroviral therapy

eIMB Ecological adaptation of the Information, Motivation and Behavioral skills

FET Fisher's exact test

FP Family planning

ICC Intra-class correlation

ITT Intent-to-treat

MoH Ministry of Health

MSI Manual self-insemination

PLHIV Persons living with HIV

PrEP Pre-exposure prophylaxis

SCC Safer conception counseling

SCM Safer conception methods

TASO The AIDS Support Organization

TCl Timed condomless intercourse

\section{Declarations}

Ethics approval and consent to participate: The study protocol was reviewed and approved by the Institutional Review Board at the RAND Corporation and Makerere University, and all participants provided written informed consent.

Consent for publication: Not applicable. 
Availability of data and materials: An anonymous dataset is available to researchers upon request to the corresponding author and review by the study team.

Competing interests: The authors declare that they have no competing interests.

Funding: Research reported in this publication was supported by the Eunice Kennedy Shriver National Institute of Child Health \& Human Development of the National Institutes of Health under Award Number R01HD090981. The content is solely the responsibility of the authors and does not necessarily represent the official views of the National Institutes of Health. The funder had no role in the design of the study, the collection, analysis and interpretation of the data, nor the writing of the manuscript.

\section{Authors' contributions:}

GW, DM, EH, JBK, VG, SFK, RW, MN, and KG contributed to the writing of the paper. GW, DM, JBK, SFK, VG, RW, EH, MN and KG contributed to the study design and intervention development. MT, MB, BGD, VS, SL and US conducted the data analysis. All authors have read and approved the final manuscript.

Acknowledgements: We would like to acknowledge the study coordinators, Jimmy Mayatsa and Simpson Nuwamanya, as well as the study participants for their willingness to participate in and dedication to the study.

\section{References}

1. Beyeza-Kashesya J, Kaharuza F, Mirembe F, Neema S, Ekstrom AM, Kulane A. The dilemma of safe sex and having children: challenges facing HIV sero-discordant couples in Uganda. Afr Health Sci. 2009;9(1):2-12.

2. Wanyenze RK, Tumwesigye NM, Kindyomunda R, Beyeza-Kashesya J, Atuyambe L, Kansiime A, et al. Uptake of family planning methods and unplanned pregnancies among HIV-infected individuals: a cross-sectional survey among clients at HIV clinics in Uganda. J Int AIDS Soc. 2011;14:35.

3. Wabwire-Mangen F. Uganda HIV prevention response and Modes of Transmission Analysis. Kampala, Uganda: National AIDS Commission; 2009.

4. Kakaire $\mathrm{O}$, Osinde MO, Kaye DK. Factors that predict fertility desires for people living with HIV infection at a support and treatment centre in Kabale, Uganda. Reprod Health. 2010;7:27.

5. Cohen MS, Chen YQ, McCauley M, Gamble T, Hosseinipour MC, Kumarasamy N, et al. Prevention of HIV-1 infection with early antiretroviral therapy. N Engl J Med. 2011;365(6):493-505.

6. UNAIDS. Uganda: Overview 2020 [Available from: https://www.unaids.org/en/regionscountries/countries/uganda.

7. Pivotal Study Finds That HIV Medications Are Highly Effective as Prophylaxis Against HIV Infection in Men and Women in Africa [press release]. 2011.

8. Vernazza PL, Graf I, Sonnenberg-Schwan U, Geit M, Meurer A. Preexposure prophylaxis and timed intercourse for HIVdiscordant couples willing to conceive a child. Aids. 2011;25(16):2005-8.

9. Gwokyalya V, Beyeza-Kashesya J, Bwanika JB, Matovu JKB, Mugerwa S, Arinaitwe J, et al. Knowledge and correlates of use of safer conception methods among HIV-infected women attending HIV care in Uganda. Reprod Health. 2019;16(Suppl 1):64.

10. Wagner GJ, Linnemayr S, Goggin K, Mindry D, Beyeza-Kashesya J, Finocchario-Kessler S, et al. Prevalence and Correlates of Use of Safer Conception Methods in a Prospective Cohort of Ugandan HIV-Affected Couples with Fertility Intentions. AIDS Behav. 2017;21(8):2479-87.

11. Bekker L, Blac V, Myer L, Rees H, Cooper D, Mall S, et al. Guidelines on Safer Conception in Fertile HIV-Infected Individuals and Couples. The Southern African Journal of HIV Medicine. 2011.

12. Davey D, West S, Umutoni V, Taleghani S, Klausner H, Farley E, et al. A Systematic Review of the Current Status of Safer Conception Strategies for HIV Affected Heterosexual Couples in Sub-Saharan Africa. Aids and Behavior. 2018;22(9):2916-46.

13. Schwartz SR, Bassett J, Mutunga L, Yende N, Mudavanhu M, Phofa R, et al. HIV incidence, pregnancy, and implementation outcomes from the Sakh'umndeni safer conception project in South Africa: a prospective cohort study. Lancet Hiv. 2019;6(7):E438-E46. 
14. Goggin K, Hurley EA, Beyeza-Kashesya J, Gwokyalya V, Finocchario-Kessler S, Birungi J, et al. Study protocol of "Our Choice": a randomized controlled trial of the integration of safer conception counseling to transform HIV family planning services in Uganda. Implement Sci. 2018;13(1):110.

15. Finocchario-Kessler S, Wanyenze R, Mindry D, Beyeza-Kashesya J, Goggin K, Nabiryo C, et al. "I May Not Say We Really Have a Method, It Is Gambling Work": Knowledge and Acceptability of Safer Conception Methods Among Providers and HIV Clients in Uganda. Health Care Women In. 2014;35(7-9):896-917.

16. Fisher JD, Fisher WA, Misovich SJ, Kimble DL, Malloy TE. Changing AIDS risk behavior: effects of an intervention emphasizing AIDS risk reduction information, motivation, and behavioral skills in a college student population. Health Psychol. 1996;15(2):114-23.

17. Goggin K, Gqaleni N, Mbhele AL, Makhathini ME, Buthelezi TD, Ndlovu SW, et al. The Translation and Cultural Adaptation of Patient-reported Outcome Measures for a Clinical Study Involving Traditional Health Providers and Bio-medically Trained Practitioners. Alternation (Durb). 2010;17(1):273-94.

18. Uganda Ministry of Health. The National Policy Guidelines and Service Standards for Sexual and Reproductive Health and Rights. Reproductive Health Division, Department of Community Health, MoH; 2011.

19. Firth D. Bias Reduction of Maximum-Likelihood-Estimates. Biometrika. 1993;80(1):27-38.

20. King G, Zeng L. Logistic regression in rare events data. Political analysis. 2001;9(2):137-63.

21. Babigumira JB, Stergachis A, Veenstra DL, Gardner JS, Ngonzi J, Mukasa-Kivunike P, et al. Potential cost-effectiveness of universal access to modern contraceptives in Uganda. PLoS One. 2012;7(2):e30735.

22. Bunger AC, Birken SA, Hoffman JA, MacDowell H, Choy-Brown M, Magier E. Elucidating the influence of supervisors' roles on implementation climate. Implementation Science. 2019;14(1).

23. Ferrari G, Torres-Rueda S, Michaels-Igbokwe C, Watts C, Jewkes R, Vassall A. Economic Evaluation of Public Health Interventions: An Application to Interventions for the Prevention of Violence Against Women and Girls Implemented by the "What Works to Prevent Violence Against Women and Girls?" Global Program. J Interpers Violence. 2019:886260519885118.

24. Goldmann L, Lundgren R, Welbourn A, Gillespie D, Bajenja E, Muvhango L, et al. On the CUSP: the politics and prospects of scaling social norms change programming. Sexual and Reproductive Health Matters. 2019;27(2):51-63.

25. Plesk P. Redesigning Health Care with Insights from the Science of Complex Adaptive Systems. Crossing the Quality Chasm: A New Health System for the 21st Century. Washington Dc: Institute of Medicine Committee on Quality of Health Care in America; 2001.

26. Wanyeze R, Makumbi F, Matovu J, Beyeza-Kashesya J, Mudiope P, Mugerwa S, et al. Family Planning and Sexual and Reproductive Health Survey among HIV Infected Individuals in HIV Care in Uganda 2017.

27. Beyeza-Kashesya J, Ekstrom AM, Kaharuza F, Mirembe F, Neema S, Kulane A. My partner wants a child: A cross-sectional study of the determinants of the desire for children among mutually disclosed sero-discordant couples receiving care in Uganda. Bmc Public Health. 2010;10.

28. Wanyenze RK, Goggin K, Finocchario-Kessler S, Beyeza-Kashesya J, Mindry D, Birungi J, et al. Utilization of prevention of mother-to-child transmission (PMTCT) services among pregnant women in HIV care in Uganda: a 24-month cohort of women from pre-conception to post-delivery. BMC Res Notes. 2018;11(1):187.

29. Goulart ACX, Farnezi HCM, França J, Santos AD, Ramos MG, Penna MLF. HIV, HPV and Chlamydia trachomatis: impacts on male fertility. JBRA Assist Reprod. 2020;24(4):492-7.

30. Khawcharoenporn T, Sha B. HIV infection and infertility. Genital Infections and Infertility2016.

\section{Tables}

\section{Table 1. Study Measures}




\section{Primary Outcomes}

Use of appropriate reproductive method to achieve stated reproductive goal (among whole sample)

Accurate use of safer conception methods (among those trying to conceive)

Use of modern contraceptives (among

those not trying to conceive)

\section{Secondary Outcomes}

Any use of SCM (among those trying to conceive)

Use of any method to prevent pregnancy (among those not trying to conceive)

Pregnancy status Whether or not female partner become pregnant during the study, confirmed via pregnancy test conducted by FP nurse.

Partner seroconversion

Partner HIV status based on rapid HIV test conducted by clinic staff at month 12 or at postpregnancy assessment.

\section{Covariates}

Demographics Age, sex, and education level (whether or not any secondary education was completed) as selfreported by client.

HIV medical and care characteristics

HIV diagnosis date, ART status, most recent CD4 count and HIV viral load were abstracted from the clients' clinic chart.

Relationship/partner characteristics Marital status, length of relationship, co-habitation with partner, partner's age, and whether partner was using HIV pre-exposure prophylaxis (PrEP), all assessed via client self-report.

Reproductive health history History of respondent or partner having biological children, having a child together, having been and behaviors tested for infertility, or a health care provider ever telling them they may have fertility problems, and whether either had been diagnosed or (and treated for) a sexually transmitted infection in the prior 6 months, via client self-report.

Table 2. Sample characteristics at baseline, by study completion and study arm 


\begin{tabular}{|c|c|c|c|c|c|c|c|c|}
\hline & $\begin{array}{l}\text { Total } \\
\text { Sample } \\
(n=389)\end{array}$ & $\begin{array}{l}\text { Study } \\
\text { completers } \\
(n=373)\end{array}$ & $\begin{array}{l}\text { Lost to } \\
\text { follow-up } \\
(n=16)\end{array}$ & & $\begin{array}{l}\text { SCC1 } \\
(n=129)\end{array}$ & $\begin{array}{l}\operatorname{scc} 2 \\
(n=130)\end{array}$ & $\begin{array}{l}\text { Usual } \\
\text { care } \\
(n=130)\end{array}$ & \\
\hline & $\begin{array}{l}\text { Mean } \\
\text { (SD)/N (\%) }\end{array}$ & $\begin{array}{l}\text { Mean (SD)/N } \\
(\%)\end{array}$ & $\begin{array}{l}\text { Mean } \\
\text { (SD)/N (\%) }\end{array}$ & $\begin{array}{l}\mathrm{P} \\
\text { value }\end{array}$ & $\begin{array}{l}\text { Mean } \\
(\text { SD)/N } \\
(\%)\end{array}$ & $\begin{array}{l}\text { Mean } \\
(\text { SD)/N } \\
(\%)\end{array}$ & $\begin{array}{l}\text { Mean } \\
(\text { SD)/N } \\
(\%)\end{array}$ & $\begin{array}{l}P \\
\text { value }\end{array}$ \\
\hline \multicolumn{9}{|l|}{$\begin{array}{l}\text { Sociodemographic } \\
\text { characteristics }\end{array}$} \\
\hline Age (years) & $35 \cdot 9(8 \cdot 2)$ & $35 \cdot 9(8 \cdot 1)$ & $34 \cdot 1(10 \cdot 5)$ & 0.372 & $\begin{array}{l}35 \cdot 1 \\
(7 \cdot 2)\end{array}$ & $\begin{array}{l}35 \cdot 3 \\
(8 \cdot 0)\end{array}$ & $37 \cdot 1(9 \cdot 1)$ & 0.095 \\
\hline Female gender & $\begin{array}{l}195 \\
(50 \cdot 3 \%)\end{array}$ & $187(50 \cdot 1 \%)$ & $8(50 \cdot 0 \%)$ & 0.992 & $\begin{array}{l}78 \\
(60 \cdot 5 \%)\end{array}$ & $\begin{array}{l}66 \\
(50 \cdot 8 \%)\end{array}$ & $\begin{array}{l}51 \\
(39 \cdot 2 \%)\end{array}$ & 0.003 \\
\hline $\begin{array}{l}\text { Some secondary } \\
\text { education }\end{array}$ & $\begin{array}{l}132 \\
(33 \cdot 9 \%)\end{array}$ & $126(33 \cdot 8 \%)$ & $6(37 \cdot 5 \%)$ & 0.758 & $\begin{array}{l}34 \\
(26 \cdot 4 \%)\end{array}$ & $\begin{array}{l}49 \\
(37 \cdot 7 \%)\end{array}$ & $\begin{array}{l}49 \\
(37 \cdot 7 \%)\end{array}$ & 0.084 \\
\hline \multicolumn{9}{|l|}{$\begin{array}{l}\text { HIV disease } \\
\text { characteristics }\end{array}$} \\
\hline $\begin{array}{l}\text { Time since HIV } \\
\text { diagnosis (years) }\end{array}$ & $10 \cdot 7(8 \cdot 7)$ & $10 \cdot 6(8 \cdot 7)$ & $13 \cdot 2(9 \cdot 7)$ & $0 \cdot 241$ & $\begin{array}{l}11 \cdot 0 \\
(9 \cdot 1)\end{array}$ & $9 \cdot 6(8 \cdot 6)$ & $11 \cdot 5(8 \cdot 5)$ & $0 \cdot 191$ \\
\hline $\begin{array}{l}\text { CD4 count } \\
\left.\text { (cells/mm } / \mathrm{mm}^{3}\right)\end{array}$ & $518(293)$ & $524(294)$ & 391 (247) & $0 \cdot 142$ & $\begin{array}{l}537 \\
(287)\end{array}$ & $\begin{array}{l}535 \\
(319)\end{array}$ & $\begin{array}{l}483 \\
(273)\end{array}$ & 0.400 \\
\hline $\begin{array}{l}\text { Undetectable HIV viral } \\
\text { load }(n=315)^{1}\end{array}$ & $\begin{array}{l}265 \\
(83 \cdot 9 \%)\end{array}$ & $255(84 \cdot 2 \%)$ & $10(76 \cdot 9 \%)$ & $0 \cdot 487$ & $\begin{array}{l}90 \\
(87 \cdot 4 \%)\end{array}$ & $\begin{array}{l}78 \\
(78 \cdot 8 \%)\end{array}$ & $\begin{array}{l}97 \\
(85 \cdot 1 \%)\end{array}$ & 0.229 \\
\hline Currently on $\mathrm{ART}^{3}$ & $\begin{array}{l}385 \\
(99 \cdot 2 \%)\end{array}$ & $369(99 \cdot 2 \%)$ & $16(100 \%)$ & 0.718 & $\begin{array}{l}129 \\
(100 \%)\end{array}$ & $\begin{array}{l}128 \\
(98 \cdot 5 \%)\end{array}$ & $\begin{array}{l}128 \\
(99 \cdot 2 \%)\end{array}$ & 0.368 \\
\hline Time on ART (years) ${ }^{2}$ & $7 \cdot 8(7 \cdot 1)$ & $7 \cdot 8(7 \cdot 1)$ & $8 \cdot 5(7 \cdot 2)$ & $0 \cdot 710$ & $7 \cdot 7(7 \cdot 5)$ & $7 \cdot 4(7 \cdot 0)$ & $8 \cdot 5(6 \cdot 7)$ & $0 \cdot 431$ \\
\hline \multicolumn{9}{|l|}{$\begin{array}{l}\text { Partner and } \\
\text { relationship } \\
\text { characteristics }\end{array}$} \\
\hline Married to partner & $\begin{array}{l}326 \\
(83 \cdot 8 \%)\end{array}$ & $312(83 \cdot 7 \%)$ & $14(87 \cdot 5 \%)$ & 0.682 & $\begin{array}{l}113 \\
(87 \cdot 6 \%)\end{array}$ & $\begin{array}{l}102 \\
(78 \cdot 5 \%)\end{array}$ & $\begin{array}{l}111 \\
(85 \cdot 4 \%)\end{array}$ & $0 \cdot 114$ \\
\hline $\begin{array}{l}\text { Length of relationship } \\
\text { (years) }\end{array}$ & $9 \cdot 9(10 \cdot 7)$ & $10 \cdot 0(10 \cdot 8)$ & $9 \cdot 6(9 \cdot 5)$ & 0.907 & $9 \cdot 3(9 \cdot 6)$ & $\begin{array}{l}9 \cdot 4 \\
(11 \cdot 1)\end{array}$ & $\begin{array}{l}11 \cdot 0 \\
(11 \cdot 3)\end{array}$ & 0.363 \\
\hline $\begin{array}{l}\text { Currently living with } \\
\text { partner }\end{array}$ & $\begin{array}{l}344 \\
(88 \cdot 4 \%)\end{array}$ & $329(88 \cdot 2 \%)$ & 15 (93.8\%) & 0.497 & $\begin{array}{l}116 \\
(89 \cdot 9 \%)\end{array}$ & $\begin{array}{l}114 \\
(87 \cdot 7 \%)\end{array}$ & $\begin{array}{l}114 \\
(87 \cdot 7 \%)\end{array}$ & 0.811 \\
\hline \multicolumn{9}{|l|}{$\begin{array}{l}\text { Reproductive history } \\
\text { and behavior }\end{array}$} \\
\hline $\begin{array}{l}\text { Using modern } \\
\text { contraceptives }\end{array}$ & $71(18 \cdot 3 \%)$ & 69 (18.5\%) & $2(12 \cdot 5 \%)$ & 0.543 & $\begin{array}{l}23 \\
(17 \cdot 8 \%)\end{array}$ & $\begin{array}{l}27 \\
(20 \cdot 8 \%)\end{array}$ & $\begin{array}{l}21 \\
(16 \cdot 2 \%)\end{array}$ & 0.622 \\
\hline $\begin{array}{l}\text { Participant has } \\
\text { biological children }\end{array}$ & $\begin{array}{l}349 \\
(89 \cdot 7 \%)\end{array}$ & $335(89 \cdot 8 \%)$ & $14(87 \cdot 5 \%)$ & 0.766 & $\begin{array}{l}118 \\
(91 \cdot 5 \%)\end{array}$ & $\begin{array}{l}112 \\
(86 \cdot 2 \%)\end{array}$ & $\begin{array}{l}119 \\
(91 \cdot 5 \%)\end{array}$ & $0 \cdot 261$ \\
\hline $\begin{array}{l}\text { Has had a child with } \\
\text { partner }\end{array}$ & $\begin{array}{l}195 \\
(50 \cdot 1 \%)\end{array}$ & $187(50 \cdot 1 \%)$ & $8(50 \cdot 0 \%)$ & 0.992 & $\begin{array}{l}59 \\
(45 \cdot 7 \%)\end{array}$ & $\begin{array}{l}63 \\
(48 \cdot 5 \%)\end{array}$ & $\begin{array}{l}73 \\
(56 \cdot 2 \%)\end{array}$ & $0 \cdot 220$ \\
\hline
\end{tabular}

${ }^{1} \mathrm{~A}$ total of 315 participants had viral load data available at baseline

${ }^{2}$ Among those on ART at baseline

${ }^{3} \mathrm{~A}$ total of 252 participants had CD4 data available at baseline

SD = standard deviation; $\operatorname{PrEP}=$ pre-exposure prophylaxis 
Table 3: Intention-to-treat comparisons of the primary outcome, SCM and contraception use between the combined intervention group and usual care control, and between the two intervention groups (SCC1 vs. SCC2), with and without covariate adjustment 


\begin{tabular}{|c|c|c|c|c|c|c|c|c|}
\hline Overall & SCC1 & SCC2 & $\begin{array}{l}\text { Sig. Test } \\
\text { (Unadjusted) }\end{array}$ & $\begin{array}{l}\text { Intervention } \\
\text { effect } \\
\text { (Covariate } \\
\text { adjusted) }\end{array}$ & $\begin{array}{l}\text { Intervention } \\
\text { (SCC1/SCC2) }\end{array}$ & $\begin{array}{l}\text { Usual } \\
\text { care } \\
\text { control }\end{array}$ & $\begin{array}{l}\text { Sig. Test } \\
\text { (Unadjusted) }\end{array}$ & $\begin{array}{l}\text { Intervention } \\
\text { effect } \\
\text { (Covariate } \\
\text { adjusted) }\end{array}$ \\
\hline & $\mathrm{N}(\%)$ & $N(\%)$ & Chi-sq & OR $(95 \% \mathrm{Cl})$ & $N(\%)$ & $N(\%)$ & Chi-sq & OR $(95 \% \mathrm{Cl})$ \\
\hline \multicolumn{9}{|c|}{ Primary outcome: SCM use or contraception use consistent with reproductive goal } \\
\hline \multicolumn{9}{|c|}{ Among all individuals in sample $(n=389)$} \\
\hline $\mathbf{N}$ & 129 & 130 & & & 259 & 130 & & \\
\hline $\begin{array}{l}\text { Used SCM } \\
\text { accurately if } \\
\text { trying to } \\
\text { conceive or } \\
\text { modern } \\
\text { contraception } \\
\text { if not trying } \\
\text { to conceive }\end{array}$ & $\begin{array}{l}35 \\
(27.1 \%)\end{array}$ & $\begin{array}{l}19 \\
(14.6 \%)\end{array}$ & 0.013 & $\begin{array}{l}4.50 * \star \star \\
(1.44- \\
14.01)\end{array}$ & $54(20.8 \%)$ & $\begin{array}{l}9 \\
(6.9 \%)\end{array}$ & $<0.001$ & $\begin{array}{l}10.63^{* \star \star} \\
(2.79- \\
40.49)\end{array}$ \\
\hline $\begin{array}{l}\text { Used SCM } \\
\text { accurately if } \\
\text { trying to } \\
\text { conceive or } \\
\text { any } \\
\text { contraception } \\
\text { (incl } \\
\text { condoms) if } \\
\text { not trying to } \\
\text { conceive }\end{array}$ & $\begin{array}{l}46 \\
(35.7 \%)\end{array}$ & $\begin{array}{l}33 \\
(25.4 \%)\end{array}$ & 0.073 & $\begin{array}{l}3.44 * * \\
(1.31- \\
9.02)\end{array}$ & $79(30.5 \%)$ & $\begin{array}{l}27 \\
(20.8 \%)\end{array}$ & 0.042 & $\begin{array}{l}3.63^{* * *} \\
(1.38- \\
9.61)\end{array}$ \\
\hline \multicolumn{9}{|l|}{ SCM use } \\
\hline \multicolumn{9}{|c|}{ Among those trying to conceive throughout study $(n=212)$ or during one 6-month period $(n=64)$ : total $n=276$} \\
\hline $\mathbf{N}$ & 104 & 87 & & & 191 & 85 & & \\
\hline $\begin{array}{l}\text { Used any (un- } \\
\text { named) } \\
\text { strategy to } \\
\text { reduce risk in } \\
\text { conceiving }\end{array}$ & $\begin{array}{l}81 \\
(77.9 \%)\end{array}$ & $\begin{array}{l}61 \\
(70.1 \%)\end{array}$ & 0.221 & $\begin{array}{l}7.05^{\star * *} \\
(2.07- \\
23.99)\end{array}$ & $142(74.3 \%)$ & $\begin{array}{l}26 \\
(30.6 \%)\end{array}$ & $<0.001$ & $\begin{array}{l}27.17 * \star * \\
(7.84- \\
94.15)\end{array}$ \\
\hline $\begin{array}{l}\text { Reported } \\
\text { using SCM } \\
\text { (TCI/MSI) }\end{array}$ & $\begin{array}{l}75 \\
(72.1 \%)\end{array}$ & $\begin{array}{l}50 \\
(57.5 \%)\end{array}$ & 0.034 & $\begin{array}{l}4.75^{* * *} \\
(1.64- \\
13.71)\end{array}$ & $125(65.4 \%)$ & $\begin{array}{l}4 \\
(4.7 \%)\end{array}$ & $<0.001$ & $\begin{array}{l}494.4^{\star * *} \\
(26.06- \\
9,378)\end{array}$ \\
\hline $\begin{array}{l}\text { Reported } \\
\text { using TCl }\end{array}$ & $\begin{array}{l}67 \\
(64.4 \%)\end{array}$ & $\begin{array}{l}42 \\
(48.3 \%)\end{array}$ & 0.025 & $\begin{array}{l}5.12 \star \star * \\
(1.86- \\
14.50)\end{array}$ & $109(57.1 \%)$ & $\begin{array}{l}4 \\
(4.7 \%)\end{array}$ & $<0.001$ & $\begin{array}{l}424.6 \text { *** } \\
(22.63- \\
7,968)\end{array}$ \\
\hline $\begin{array}{l}\text { Reported } \\
\text { accurate TCl }\end{array}$ & $\begin{array}{l}30 \\
(28.8 \%)\end{array}$ & $\begin{array}{l}9 \\
(10.3 \%)\end{array}$ & 0.002 & $\begin{array}{l}10.33^{* \star *} \\
(2.60- \\
41,08)\end{array}$ & $39(20.4 \%)$ & $0(0 \%)$ & $<0.001$ & $\begin{array}{l}121.9 * \star * \\
(6.30- \\
2,360)\end{array}$ \\
\hline $\begin{array}{l}\text { Reported } \\
\text { using MSI } \\
\text { (among } \\
\text { females) }\end{array}$ & $\begin{array}{l}14 / 69 \\
(20.3 \%)\end{array}$ & $\begin{array}{l}8 / 39 \\
(20.5 \%)\end{array}$ & 0.978 & $\begin{array}{l}1.06(0.27 \text { - } \\
4.11)\end{array}$ & $\begin{array}{l}22 / 108 \\
(20.4 \%)\end{array}$ & $\begin{array}{l}0 / 34 \\
(0 \%)\end{array}$ & 0.002 & $\begin{array}{l}9.88(0.48 \text { - } \\
201.9)\end{array}$ \\
\hline $\begin{array}{l}\text { Reported } \\
\text { accurate MSI }\end{array}$ & $\begin{array}{l}8 / 69 \\
(11.6 \%)\end{array}$ & $\begin{array}{l}1 / 39 \\
(2.6 \%)\end{array}$ & 0.152 & $\begin{array}{l}1.13(0.13- \\
9.54)\end{array}$ & 9/108 (8.3\%) & $\begin{array}{l}0 / 34 \\
(0 \%)\end{array}$ & 0.114 & $\begin{array}{l}2.77(0.11- \\
67.26)\end{array}$ \\
\hline $\begin{array}{l}\text { Used TCl or } \\
\text { MSI } \\
\text { accurately }\end{array}$ & $\begin{array}{l}36 \\
(34.6 \%)\end{array}$ & $\begin{array}{l}10 \\
(11.5 \%)\end{array}$ & $<0.001$ & $\begin{array}{l}6.43 * * * \\
(1.90- \\
21.73)\end{array}$ & $46(24.1 \%)$ & $0(0 \%)$ & $<0.001$ & $\begin{array}{l}91.84 \text { *** } \\
(4.94- \\
1,709)\end{array}$ \\
\hline $\begin{array}{l}\text { Secondary } \\
\text { outcome: } \\
\text { became } \\
\text { pregnant }\end{array}$ & $\begin{array}{l}32 \\
(30.8 \%)\end{array}$ & $\begin{array}{l}29 \\
(33.3 \%)\end{array}$ & 0.760 & $\begin{array}{l}0.44(0.15- \\
1.25)\end{array}$ & 61 (31.9\%) & $\begin{array}{l}27 \\
(31.8 \%)\end{array}$ & 0.902 & $\begin{array}{l}0.73(0.25- \\
2.09)\end{array}$ \\
\hline
\end{tabular}




\section{Contraception use}

\section{Among those not trying to conceive throughout study $(n=113)$ or in one 6 -month time period $(n=64)$ : total $n=177$}

\begin{tabular}{|c|c|c|c|c|c|c|c|c|}
\hline $\mathbf{N}$ & 48 & 61 & & & 109 & 68 & & \\
\hline $\begin{array}{l}\text { Using } \\
\text { modern } \\
\text { contraceptive }\end{array}$ & $\begin{array}{l}7 \\
(14.6 \%)\end{array}$ & $\begin{array}{l}12 \\
(19.4 \%)\end{array}$ & 0.487 & $\begin{array}{l}3.72(0.37- \\
37.48)\end{array}$ & 19 (17.4\%) & $\begin{array}{l}12 \\
(17.6 \%)\end{array}$ & 0.971 & $\begin{array}{l}1.20(0.22- \\
6.501\end{array}$ \\
\hline $\begin{array}{l}\text { Using } \\
\text { modern } \\
\text { contraceptive } \\
\text { or always use } \\
\text { condoms or } \\
\text { not having } \\
\text { sex }\end{array}$ & $\begin{array}{l}28 \\
(58.3 \%)\end{array}$ & $\begin{array}{l}35 \\
(56.5 \%)\end{array}$ & 0.92 & $\begin{array}{l}1.07(0.28- \\
4.19)\end{array}$ & $63(57.8 \%)$ & $\begin{array}{l}37 \\
(54.4 \%)\end{array}$ & 0.658 & $\begin{array}{l}0.52(0.16- \\
1.75)\end{array}$ \\
\hline $\begin{array}{l}\text { Always use } \\
\text { condoms }\end{array}$ & $\begin{array}{l}13 \\
(27.1 \%)\end{array}$ & $\begin{array}{l}16 \\
(25.8 \%)\end{array}$ & 0.92 & $\begin{array}{l}2.78(0.50- \\
15.63)\end{array}$ & 29 (26.6\%) & $\begin{array}{l}18 \\
(26.5 \%)\end{array}$ & 0.984 & $\begin{array}{l}2.66(0.57- \\
12.44)\end{array}$ \\
\hline $\begin{array}{l}\text { Secondary } \\
\text { outcome: did } \\
\text { NOT become } \\
\text { pregnant }\end{array}$ & $\begin{array}{l}44 \\
(91.7 \%)\end{array}$ & $\begin{array}{l}54 \\
(88.5 \%)\end{array}$ & 0.589 & $\begin{array}{l}1.40(0.17- \\
11.58)\end{array}$ & 98 (89.9\%) & $\begin{array}{l}61 \\
(89.7 \%)\end{array}$ & 0.965 & $\begin{array}{l}0.18(0.01- \\
4.30)\end{array}$ \\
\hline
\end{tabular}

*** $p<0.01, * * p<0.05, * p<0.1$. adjusted models controlled for site, age, sex, education, time since HIV diagnosis, marital status, length of relationship, and whether had child with partner. SCM = safer conception method; $\mathrm{TCI}=$ timed condomless sex; $\mathrm{MSI}=$ manual self-insemination; SCC1 = safer conception counseling implemented with high intensity approach; SCC2 = safer conception counseling implemented with low intensity approach; $\mathrm{OR}=$ odds ratio; $\mathrm{Cl}=$ confidence interval

\section{Figures}

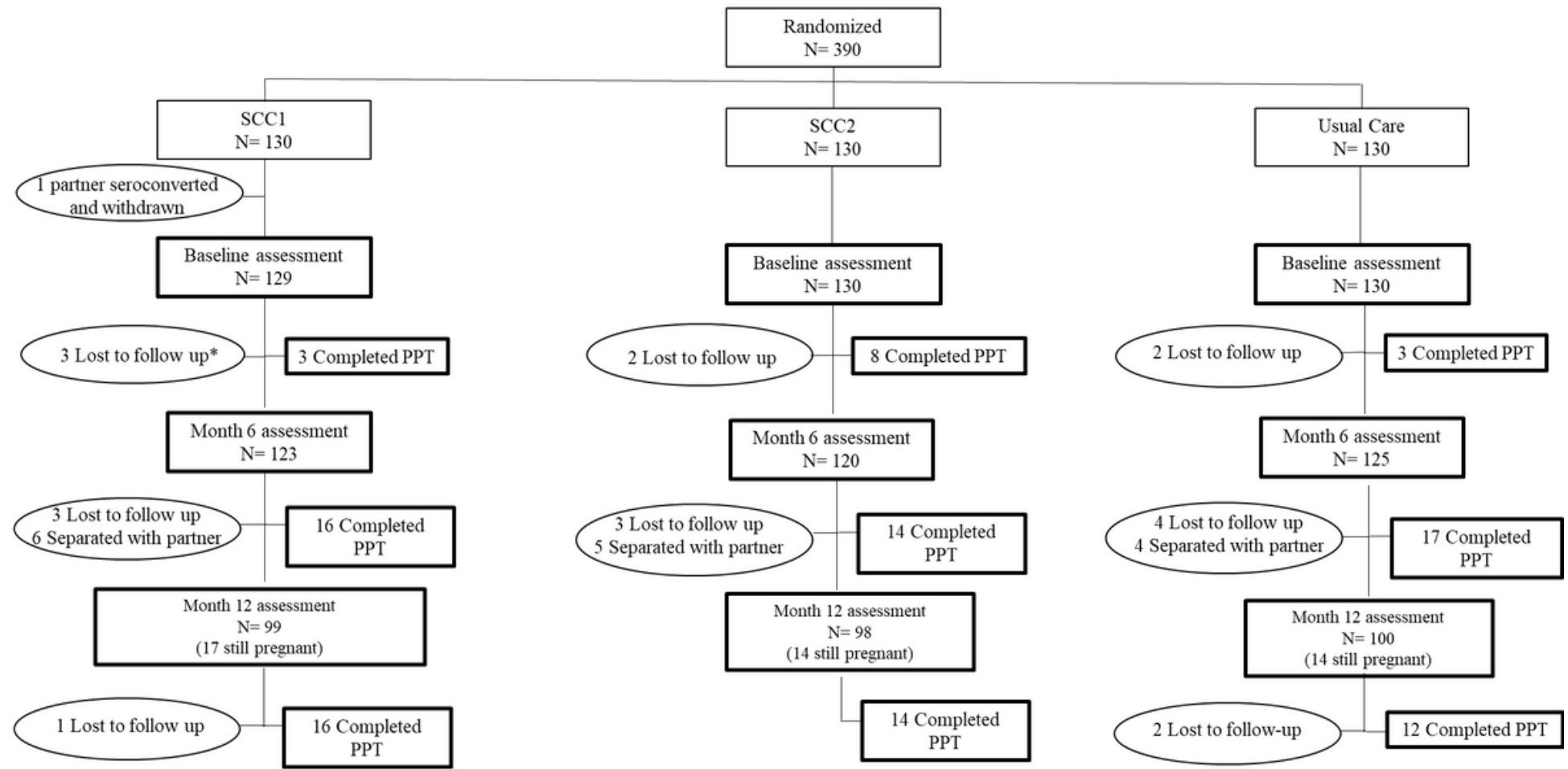

* 1 participant missed month 6 assessment and returned for month 12 PPT $=$ Post pregnancy completion assessment

\section{Figure 1}




\section{Supplementary Files}

This is a list of supplementary files associated with this preprint. Click to download.

- CONSORTExtensionforClusterTrials2012Checklist.docx

- SuppFigure1.pptx

- SuppTable1.docx

- SuppTable2.docx

- SuppTable3.docx

- SUpptable4.docx 